\title{
Stature Estimation from Index and Ring Finger in Kashmiri Population
}

\author{
Riya Gupta ${ }^{1} \&$ Surender Singh Sehrawat ${ }^{2}$ \\ ${ }^{I}$ M.Sc. Forensic Science and Toxicology, Department of Forensic Science and Toxicology, Chandigarh University, Mohali, Punjab. \\ ${ }^{2}$ Assistant Professor, Department of Forensic Science and Toxicology, Chandigarh University, Mohali, Punjab. \\ Email: riyugupta1996@gmail.com ${ }^{1} \&$ surendersehrawat.uips@cumail.in ${ }^{2}$
}

DOI: http://doi.org/10.38177/ajast.2020.4403

Copyright: (92020 Riya Gupta et al. This is an open access article distributed under the terms of the Creative Commons Attribution License, which permits unrestricted use, distribution, and reproduction in any medium, provided the original author and source are credited.

\section{ABSTRACT}

Background: Estimation of stature plays a very important role in personal identification and medico legal examination in activities like mass disaster, bomb explosive, air crash, terror etc. For the purpose of identification, it becomes quite easy when whole of the body is available but in cases where the only the fragments of body found, it becomes extreme difficult to continue with the process of identification. Aim: The aim of this study is to find regression equation through hand various measurements particularly in Kashmiri Pandit's with pure trait residing in territory of Jammu, India Subject and Method: For this study, 126 females and 144 males with age groups 20-45 years were taken. Length of both the hand was done with the help of vernier caliper from bracelet crease to the tip of middle finger, length of index and ring finger was measured from proximal flexion to their respective tips while the hand breadth was taken with vernier caliper from meta carpel radiale to meta carpel ulnar. The total height of the individual was measured with anthropometric scale and all these measurements were done after informed consent. Data was analyzed with the help of SPSS-16 using basic statistics -linear regression, multiple regression and t-test. Results: Significant co-relations between stature and entire hand dimensions were established except the hand breadth. The highest co relation with the stature was observed with hand length and ring finger than the other variables. Linear and multiple regression were calculated separately for males and females. Conclusion: The present study has provided with regression equations from various hand parameters that can be applied for stature estimation only in Kashmiri Pandit population only.

Keywords: Stature, Jammu, Identification, Kashmiri pandits.

\section{Introduction}

Forensic Anthropology is the branch of science that deals with the study of human remains in medico-legal aspects. The one of the basic aims of medico-legal inspection is to provide identification to the individual (1). The fundamental responsibility of forensic anthropologist is to perusal the skeleton and provides the description of the person based on - age, sex, stature and race which are commonly called as "big four" of anthropology. These above mentioned profile must helpful in the recognition of the individual and directly and indirectly associate the evidence (provided) from the skeleton remains to know the cause of death (2). STATURE is the distance from human feet to the vertex, when standing in erect position. The stature of the individual increases during childhood but decreases during old-age. The measurement of a particular bone of an individual directly links towards its total height (3). Estimation of stature lies between the anthropology and the identification (4). Identification is an individual birth right. Identification of the individual through stature becomes very easy when whole of the body is found at crime scene, but in certain cases like genocide, mass disaster, plane crash, terrorist attacks, unexplained natural death, war crimes and many more when dismembered body parts or amputated limbs of the body are found at such situations Forensic Anthropologist are used to assist the case, where it becomes extremely difficult $(5,6)$. The importance of taking index and ring finger for stature estimation was due to its size, during above mentioned cases there are maximum chances of attaining small bones which are however beneficial for forensic experts to proceed up with the case. There are two methods for estimating the stature of an individual I.e. mathematical method and anatomical method (7). Mathematical method includes stature estimation through independent variables through which one can generate a formula used for specific population/ community where as anatomical 


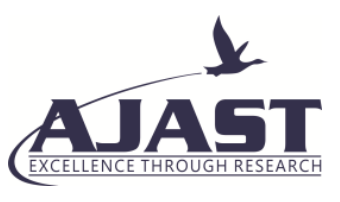

Asian Journal of Applied Science and Technology Volume 4, Issue 4, Pages 21-37, October-December 2020 method includes height of skull, length of vertebral column, length of lower limb is measured (8). Various studies have been done for stature estimation through long bones- their fragments, skull, scapula, hip bone and small bones of foot, hand and very few studies have been conducted over shoulder girdle, pelvic girdle and the cranium (9). Along with that various different methods have been used in the past years for stature estimation that are:-

1. Ratio method that was used in $19^{\text {th }}$ century.

2. Regression method is the precise and accurate method use nowadays.

3. Anatomical method is one of the most precise methods and is used when the measurements of all bones required for stature estimation is present.

\section{Origin of Ratio Method}

This method was given by a surgeon Jean Joseph Sue in Paris. Later Mathieu Orifila and Octave Lesueur in their book published about the various measurements of length of femur, tibia, fibula, humerus, ulna and radius. Later on a surgeon named George Murray Humphry gave a mathematical equation for stature estimation,

$\mathrm{Y}^{\wedge}=\mathrm{rX}$

Where, $\mathrm{Y}^{\wedge}=$ stature estimation, $\mathrm{X}=$ length of the chosen long bone.

Thus, we can write it as,

$\mathrm{r}=\mathrm{X}^{-} / \mathrm{Y}^{-}$

Where, $\mathrm{Y}^{-}=$average stature

$\mathrm{X}^{-}=$average length of the bone. Particularly, this equation represents ratio method for stature estimation.

\section{Origin of Regression Method}

This method was given by Manouvrier in 1893 and proposed two terms that are Macroskeles as the individuals with long limbs contrast to their stature and Microskeles as the individuals with short limbs. Thus, mathematically

$\mathrm{Y}^{\wedge}=\mathrm{a}+\mathrm{bX}+\mathrm{c} \mathrm{X}^{2}$

After few years, Pearson rejected the concept of Manouvrier and proposed linear regression for stature estimation and derived mathematically as;

$\mathrm{Y}^{\wedge}=\mathrm{S}_{\mathrm{Y}} / \mathrm{S}_{\mathrm{X}} \mathrm{R}_{\mathrm{XY}} \mathrm{X}+\left[\mathrm{Y}^{-}-\mathrm{S}_{\mathrm{Y}} / \mathrm{S}_{\mathrm{X}} \mathrm{R}_{\mathrm{XY}} \mathrm{X}^{-}\right]$

Where; $\mathrm{Y}^{-}=$mean stature of reference sample, $\mathrm{X}^{-}=$mean length of selected bone, $\mathrm{S}_{\mathrm{Y}}=$ standard deviation of stature, $S_{X}=$ standard deviation of parallel long bone, $R_{X Y}=$ Pearson coefficient.

\section{Origin of Anatomical Method}

This method was given by Thomas Dwight and according to him total height of an individual is the sum of various bones. Thus, mathematically,

$\mathrm{Y}=\mathrm{K}+\mathrm{A}$ 
Asian Journal of Applied Science and Technology Volume 4, Issue 4, Pages 21-37, October-December 2020

Apart from identification, stature of a particular community directly links to the person's nutrition, health ,genetic makeup, climatic conditions and many more (11). While in children stature estimation helps in the judgement of following parameters such as lung volume, muscular strength, and metabolic rate (12). The measurements that are taken in anthropology are called "anthropometry" and ALPHONSE BERTILLION (1853-1914) known as father of anthropometry (13). According to various studies, climate do play an important role in stature estimation and on this basis there are two rules;- Bergmann's rule states that individual residing in cold climate tends to be larger than those residing in warm climate; Allen's rule states opposite of Bergmann rule (14). The measurements from the various parts of the human body are useful for different purposes like:-

\section{A. In Scientific Investigations}

B. Anthropologists consider the significant evolutionary difference in different body proportions. Human population shows similar habitat variations.

C. In Medical Surgical and Dental Purposes; Anthropometry used to estimate and correlate bodily defects.

D. Criminals and Other Identifications; Anthropometry is widely used for the identification of individuals hence; it is acceptable for the identification of criminals by the different dimensions on the human body (15).

The stature (height) is one of the necessary parameter of either partial or complete identification of the individual's(16).Different studies have been given by various scientists to estimate the stature from different body parts.In conclusion, various body parts have definite and linear relationship to height of the person (17).

\section{Aim and Objectives}

\section{Aim}

Estimation of Stature from Index Finger and Ring Finger in Kashmiri Population.

\section{Objectives}

The objectives of this investigation are:-

a. To study anthropometric index and ring finger dimensions of Kashmiri population.

b. To examine the height in Kashmiri Pandits through their fingers measurement.

c. The three anthropometric measurements are taken i.e. stature, length of index finger of both the hands and length of ring finger of both the hands.

\section{Material and Methods}

\section{Material}

Population:- For the present study,270 individuals (including 126 females and 144 males) from pure Kashmiri Pandit background were taken.

Area of inclusion:-

1. All the samples were taken from pure trait which was living in Jammu region from more than 20 years. 


\section{AJAST}

Asian Journal of Applied Science and Technology

Volume 4, Issue 4, Pages 21-37, October-December 2020

2. The individuals were of $20-45$ years.

Area of exclusion:-

1 Individuals were excluded whose hand or either of the finger was broken or fractured.

2 Individual with any kind of deformility.

3 Age below 20 years and above than 45 years,

\section{Method}

\section{Stature (Standing Height)}

The subject was requested to stand barefoot in the normal standing position. The body of the subject should be straight, erect and both the heels should be slightly distance from each other. The total height and height up to the shoulder (acromion) was measured in centimetres. The eyes of the individual should be straight and head should lie in Frankfurt horizontal plane. And the measurement should be taken with the help pf anthropometric (fig.1).

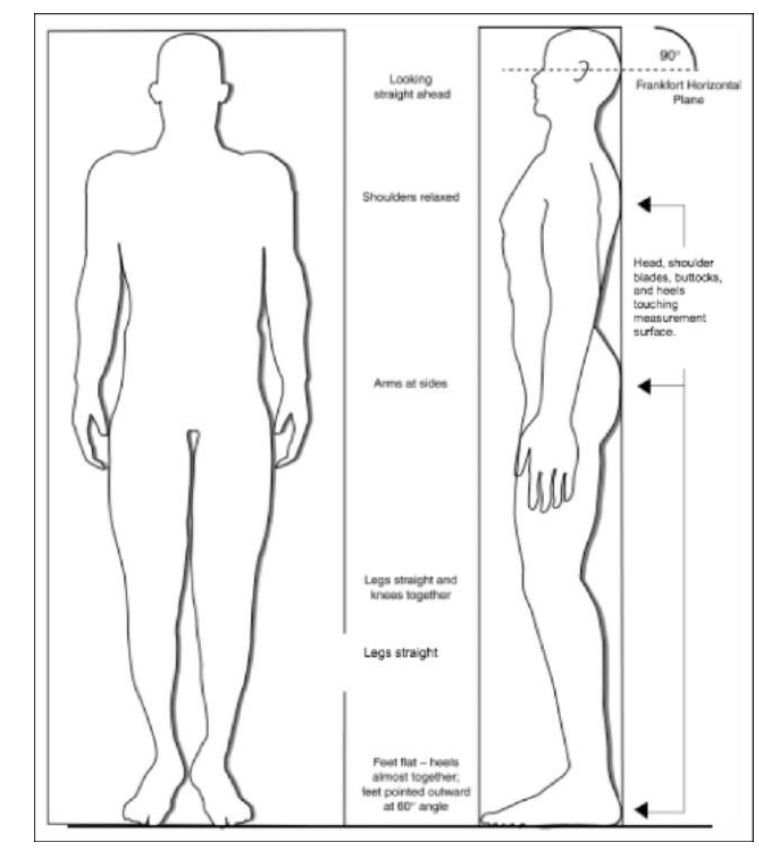

\section{Hand Length}

The subject was requested to place its hand on the flat surface like table, and measurement was taken with the help of vernier caliper. The total length of the hand was measured from the tip of middle finger to the distal wrist crease.

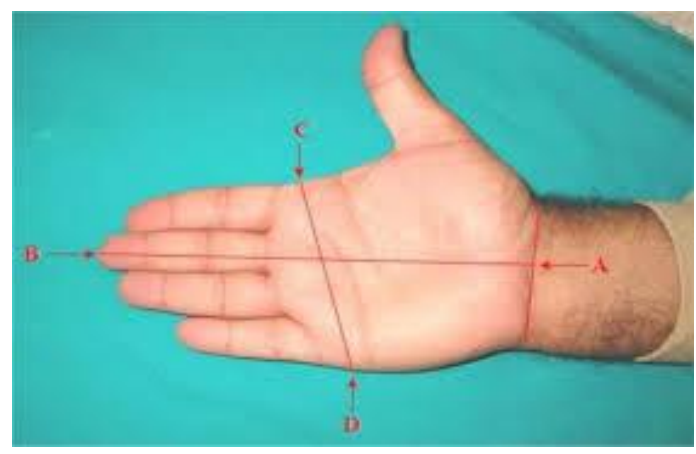

Fig.2- showing hand length $=\mathrm{AB}$ and hand breadth $=\mathrm{CD}$ 


\section{Length of Index and Ring Finger}

The distance measured from the tip of index or /and ring finger to the proximal flexion crease with the help of vernier caliper.

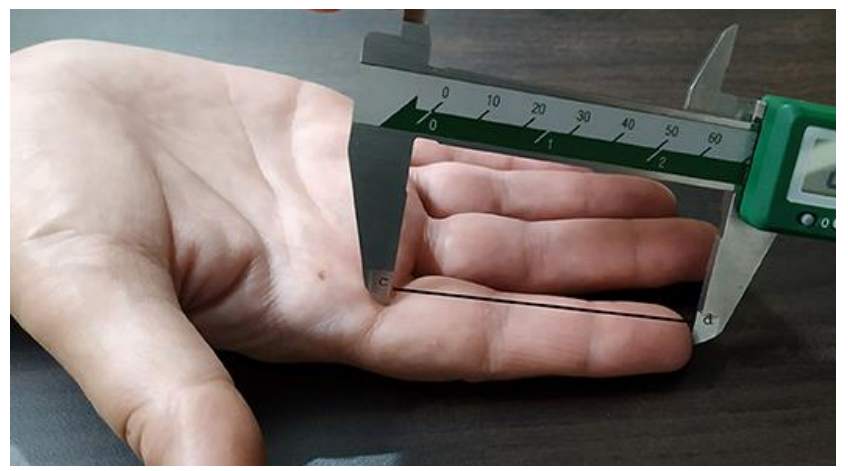

Fig.3- showing index finger length

\section{Hand Breath}

The hand breadth of the individual was also taken on flat surface and that too with the help of vernier caliper. The hand breadth of the individual was taken from the lateral point of the head of the second meta carpel to the most medial point on the head of the fifth meta carpel as this type of research design was of cohort type. The data obtained were computed and analyzed with SPSS (16 version) software and various other correlation that includes linear regression, t-test, Pearson correlation were applied in-order to find out the stature from index and ring finger respectively. The accuracy for estimating the stature from index and ring finger was determined with the help of $\mathrm{P}$ value, SEE, r, r square and linear regression equation individually.

\section{Observations}

a) Table (1) showing age of individuals:-

\begin{tabular}{|l|l|l|l|}
\hline Category & Min. age & Max. age & Mean \\
\hline Female & 20 & 45 & 42 \\
\hline Male & 20 & 45 & 43 \\
\hline
\end{tabular}

b) Table (2) showing stature of individuals:-

\begin{tabular}{|l|l|l|l|}
\hline Category & Min. stature & Max. stature & Mean \\
\hline Female & 140.20 c.m. & 179.83 c.m. & 161.63 c.m. \\
\hline Male & 152.04 c.m. & 188.97 c.m. & 173.73 c.m. \\
\hline
\end{tabular}

\section{Result and Discussion}

\section{Results}

The mean stature for females was $139.22 \mathrm{~cm}$ with 8.40 as Standard Deviation (SD). While the hand length and hand breadth mean was between $16.91 \mathrm{~cm}-17.02 \mathrm{~cm}$ with 0.89 as SD and $7.73 \mathrm{~cm}-7.86 \mathrm{~cm}$ with 0.50 as SD respectively. 


\section{NUAST}

Asian Journal of Applied Science and Technology

Volume 4, Issue 4, Pages 21-37, October-December 2020

On the other side, mean value for index and ring finger was $6.83 \mathrm{~cm}-6.86 \mathrm{~cm}$ with 0.49 as SD and $6.89 \mathrm{~cm}-6.92 \mathrm{~cm}$ with 0.49 as SD respectively. Contrarily the mean stature for males was $146.82 \mathrm{~cm}$ with $8.63 \mathrm{SD}$. While the hand length and hand breadth mean was $18.48 \mathrm{~cm}-18.50 \mathrm{~cm}$ with $0.89 \mathrm{SD}$ and $8.66 \mathrm{~cm}-8.77 \mathrm{~cm}$ with $0.61 \mathrm{SD}$ respectively. On the other side, mean value for index and ring finger was $7.37 \mathrm{~cm}-7.42 \mathrm{~cm}$ with $0.55 \mathrm{SD}$ and $7.46 \mathrm{~cm}-7.51 \mathrm{~cm}$ with $0.55 \mathrm{SD}$ respectively. In both the cases the $\mathrm{p}$ value was $<0.001$ as described in Table 3 . The standard deviation in case of both sexes, index and ring finger were similar. New regression equations were formed from obtained linear regression analysis and the stature and a new formula will be generated.

Table 3: Descriptive statistics of both the sexes of stature and different variables

\begin{tabular}{|l|l|c|c|c|}
\hline SEX & VARIABLE & MINIMUM MEAN & MAXIMUM MEAN & SD \\
\hline \multirow{5}{*}{ Female } & stature & & 139.22 & 8.40 \\
\cline { 2 - 5 } & Hand length & 16.91 & 17.02 & 0.89 \\
\cline { 2 - 5 } & Hand breadth & 7.73 & 7.86 & 0.50 \\
\cline { 2 - 5 } & Index finger & 6.83 & 6.86 & 0.49 \\
\cline { 2 - 5 } & Ring finger & 6.89 & 6.92 & 0.49 \\
\hline \multirow{5}{*}{ Males } & stature & & 146.82 & 8.63 \\
\cline { 2 - 5 } & Hand length & 18.48 & 18.50 & 0.89 \\
\cline { 2 - 5 } & Hand breadth & 8.66 & 8.77 & 0.61 \\
\cline { 2 - 5 } & Index finger & 7.37 & 7.42 & 0.55 \\
\cline { 2 - 5 } & Ring finger & 7.46 & 7.51 & 0.55 \\
\hline
\end{tabular}

And from the above studied, the formula that is generated through Linear Regression Equation in case of both Kashmiri males and females are:-

\section{In Males Left hand}

LIF (left index finger) $=134.855+5.277($ LIF $)$

LRF (left ring finger) $=130.174+5.803($ LRF $)$

LHB (left hand breadth) $=135.258+4.445($ LHB $)$

LPL (left palm length) $=138.716+3.185($ LPL)

LHL (left hand length $)=88.387+4.613($ LHL $)$

\section{In Males Right hand}

RIF (right index finger $)=134.763+5.253($ RIF $)$ 
$\mathrm{RRF}$ (right ring finger) $=128.827+6.016(\mathrm{RRF})$

RHB (right hand breadth) $=137.095+4.180($ RHB $)$

RPL (right palm length $)=88.858+4.702($ RPL $)$

RHL (right hand length $)=137.212+3.319$ (RHL)

\section{In Females Left hand}

LIF (left index finger) $=115.449+6.939($ LIF $)$

LRF (left ring finger) $=118.812+6.356(\mathrm{LRF})$

LHB $($ left hand breadth $)=123.937+5.030($ LHB $)$

LPL $($ left palm length $)=120.422+4.202($ LPL $)$

LHL (left hand length $)=90.547+4.246($ LHL $)$

\section{In Females Right hand}

$\mathrm{RIF}$ (right index finger) $=118.518+6.459(\mathrm{RIF})$

$\mathrm{RRF}$ (right ring finger) $=116.227+6.761(\mathrm{RRF})$

RHB (right hand breadth $)=125.511+4.768($ RHB $)$

RPL $($ right palm length $)=119.634+4.318($ RPL $)$

RHL (right hand length) $=87.147+4.476($ RHL $)$

The present study for the estimation of stature from length of index finger, ring finger, palm length, hand length and hand breadth in case of both the males and the females.

The " $\mathrm{P}$ " value is 0.001 for all the above mentioned parameters as mentioned above in case of both males and females which indicates that all those parameters can be calculated with high significance value.

Summary for regression equation derived from SPSS 16.0 for all mentioned parameters in table no. 04,05.

\section{Males (Table 4)}

\begin{tabular}{|c|l|c|c|c|}
\hline S.NO. & \multicolumn{1}{|c|}{ Parameters } & R value & $\mathrm{R}^{2}$ value & SEE \\
\hline 1 & Left index finger & .364 & .133 & 7.49 \\
\hline 2 & Right index finger & .368 & .135 & 7.48 \\
\hline 3 & Left ring finger & .405 & .164 & 7.35 \\
\hline 4 & Right ring finger & .423 & .179 & 7.28 \\
\hline 5 & Left hand breadth & .351 & .123 & 7.53 \\
\hline
\end{tabular}




\begin{tabular}{|c|l|c|c|c|}
\hline 6 & Right hand breadth & .318 & .101 & 7.62 \\
\hline 7 & Left palm length & .312 & .097 & 7.64 \\
\hline 8 & Right palm length & .301 & .091 & 7.66 \\
\hline 9 & Left hand length & .521 & .271 & 6.86 \\
\hline 10 & Right hand length & .518 & .269 & 6.87 \\
\hline
\end{tabular}

\section{Females (Table 5)}

\begin{tabular}{|c|l|l|l|l|}
\hline S.NO. & \multicolumn{1}{|c|}{ Parameter } & \multicolumn{1}{|c|}{$\mathrm{R}$ value } & \multicolumn{1}{c|}{$\mathrm{R}^{2}$ value } & \multicolumn{1}{|c|}{ SEE } \\
\hline 1 & Left index finger & .437 & .191 & 7.14 \\
\hline 2 & Right index finger & .405 & .164 & 7.30 \\
\hline 3 & Left ring finger & .390 & .152 & 1.17 \\
\hline 4 & Right ring finger & .427 & .183 & 7.47 \\
\hline 5 & Left hand breadth & .337 & .114 & 7.58 \\
\hline 6 & Right hand breadth & .294 & .087 & 7.40 \\
\hline 7 & Left palm length & .360 & .129 & 7.41 \\
\hline 8 & Right palm length & .357 & .127 & 6.95 \\
\hline 9 & Left hand length & .482 & .232 & 6.86 \\
\hline 10 & Right hand length & .502 & .252 & \\
\hline
\end{tabular}

\section{Discussions}

In this present study a co relation between stature and various other parameters play a very important role in estimating the stature among males and females of 20- 45 years age. When compared among the sexes it was found that males have higher values than that of females as shown below. A recent study that was performed by Rahule et.al in 2013 among Indian population where he studied about a co-relation among right middle finger length and stature of an individual in males and females and concluded that the higher co-relation exists in females than in males. Another study done by Kewal et al. in 2012 in North Indian adolescent where he studied about index and ring finger length and concluded that the higher co-relation exists in males than the females similar to our study. Another study performed by Koulapur. V.et.al. In 2017 in North Karnataka population where he estimated the stature of the desired population through length of their middle finger and concluded that stature can be best co-related in males rather than females. Yet another study done by Ahmed M. et.al in 2017 in Kashmiri population where he estimated the stature through their hand length and hand breadth and concluded that stature can be best estimated in males through the parameters mentioned above. 
This paper particularly defines about the stature estimation in Kasmhiri Pandit's population through index and ring finger of both the hands. And came up with the value of $\mathrm{R}^{2}$. The value of $\mathrm{R}^{2}$ is directly linked in stature explained by various hand measurements in both males and females. When $\mathrm{R}^{2}$ was calculated between statures and variables (LHL,RHL,LIF,RIF,LRF,RRF,LPL,RPL,LHB,RHB) the highest value of $\mathrm{R}^{2}$ was found different in different gender along with different formula.

In case of females-

For left hand; LHL AND LIF have high value of $\mathrm{R}^{2}$ with formula

$\mathrm{LHL}=90.547+4.246(\mathrm{LHL})$

$\mathrm{LIF}=115.449+6.939(\mathrm{LIF})$

For right hand; RHL AND RRF have high value of $\mathrm{R}^{2}$ with formula

$\mathrm{RHL}=87.147+4.476(\mathrm{RHL})$

$\mathrm{RRF}=116.227+6.761(\mathrm{RRF})$

In case of males-

For left hand; LHL AND LRF have high value of $\mathrm{R}^{2}$ with formula

LHL $=88.387+4.613($ LHL $)$

$\mathrm{LRF}=130.774+5.803(\mathrm{LRF})$

For right hand; RHL AND RRF have high value of $\mathrm{R}^{2}$ with formula

RHL $=137.212+3.319($ RHL $)$

$\mathrm{RRF}=128.827+6.016(\mathrm{RRF})$

\section{Conclusion}

Estimation of stature is the most important aspects in cases of identification, anthropological evidences in those cases where dismembered body parts are found. Regression equations from both the sexes with different parameters are found through this study. Stature estimation can be best predicted in males through ring finger or middle finger rather than in females in Kasmhiri Pandit's population. In this study we define separate regression equation for different hand parameters for both the sexes in Kashmiri Pandit's Population. The formulas that we defined are mentioned above with their respective parameters. These results are only being applied on Kashmiri Pandit's population and not on Kashmiri Muslim or any other population residing in J\&K.

\section{References}

[1] Krishan K., Kanchan T, Asha N. Estimation of stature from index and ring finger length in a North Indian adolescent population. J. Forensic Leg. Med. 2012;19:285-290.

[2] M.P. Evison, J. and Williams R. Forensic anthropology and human identification from the skeleton. Handbook of Forensic Sci. 2009;10:84-112. 
[3] Sjovold T. Stature estimation from the skeleton. Ency. Forensic Sci. 2000; 1:276-284.

[4] Jasuja O.P., Singh G. Estimation of stature from hand and phalange length. J. Indian Acad. Forensic Med. 2004;26(3):971-973.

[5] Choudhary S, Singh H,Gupta N. Estimation of stature from combined length of forearm and hand in Jammu region of India.J. Basic Appl. Sci. 2014; 3(1):8-10.

[6] Quinney P.R., Mallett X., Black S.M. Forensic Anthropology. AM J. Forensic Sci. 2011; 139(1):8-10.

[7] Prasad A.K., Hiwarkar M.P., Kumar A., Taywade O.K. Stature estimation from head length and breadth by regression analysis in Madhya Pradesh population. Int. J anat radiol surg.2019; 8(3):22-24.

[8] Duyar I., Pelin C, Zagyapan R. A new method of stature estimation for forensic anthropological application. $J$. Anthropol. Sci. 2006;114:23-27.

[9] Krishan K., Kanchan T, Asha N. Estimation of stature from index and ring finger length in a North Indian adolescent population. J. Forensic Leg. Med. 2012;19:285-290.

[10] Zeman T, Kralik M, Benus R. History of human stature estimation based on skeletal remains. Mikulov Anthropology Meeting.2015;20:171-175.

[11] Sunil, Dikshit P.C., Aggrawal A., Rani M. Estimation of stature from hand length. J. Indian Acad Forensic Med. 2005; 27(4):219-221.

[12] Khan M.A., Bashir S.I., Khan M.A., Shahdad S. Determination of stature from measurements of hand length and hand breadth; An anthropometric study of Kashmiri population. Int J Anat Res. 2017;5(2.3):3968-75.

[13] Singh B.K. Assessment of stature from hand and phalange length. Int J. Med. Health Resrch.2007;3:136-137.

[14] Sjovold T. Stature estimation from the skeleton. Ency. Forensic Sci. 2000; 1:276-284.

[15] Koulapur V, Sekhar B.C., Porwal R, Ali K, Honnungar RS, Pujar SS. Estimation of stature from middle finger length. Int. J. Forensic Med. Toxicol. Sci. 2017; 2(1):8-12.

[16] Bhatnagar D.P., Thapar S.P., and Batish M.K. Identification of personal height from the somatometry of the hand in Punjabi males. Forensic Sci. J.1984; 24:137-141.

[17] Jakhar J.K., Pal V., Paliwal P.K. Estimation of Height from measurement of foot length in Haryana region. $J$. Indian Acad. Forensic Med. 2001; 32(3): 231-233. 


\section{AUAST}

\section{Appendix}

\section{Graphs}

1. Graph showing right index and right ring finger in females-

\section{Chart Title}

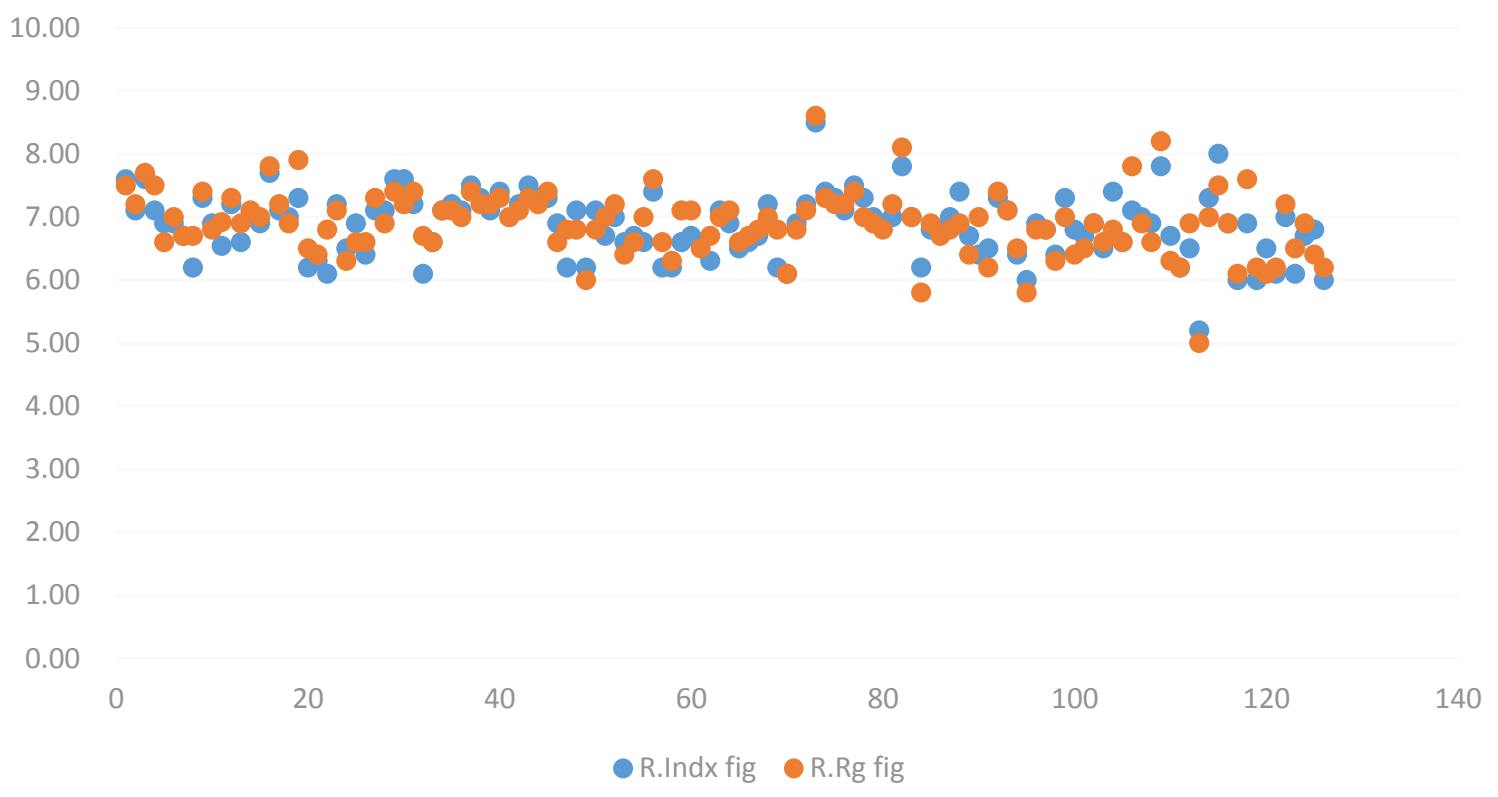

2. Graph showing left index and left ring finger in females-

\section{Chart Title}

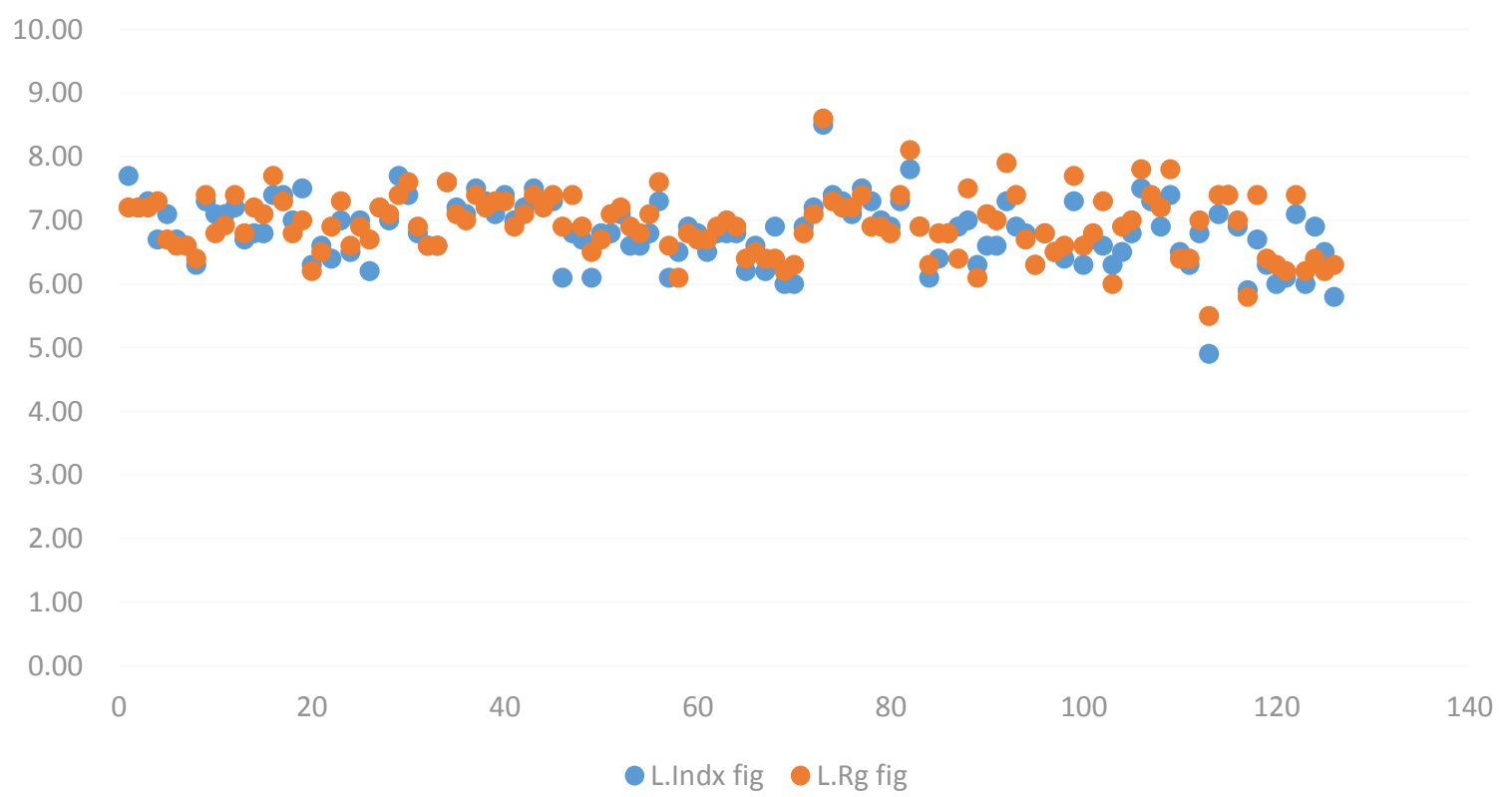




\section{AJAST}

3. Graph showing right and left hand length in case of females-

\section{Chart Title}

25.00

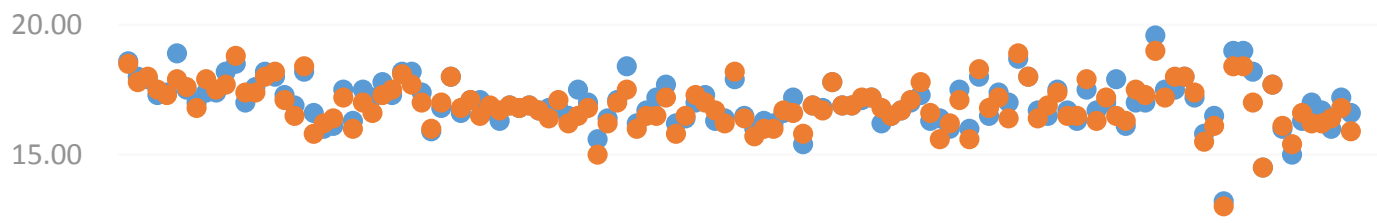

10.00

5.00

0.00

$\begin{array}{llllllll}0 & 20 & 40 & 60 & 80 & 100 & 120 & 140\end{array}$

L.H.L. R.H.L.

4. Graph showing right index and right ring in case of males-

\section{Chart Title}

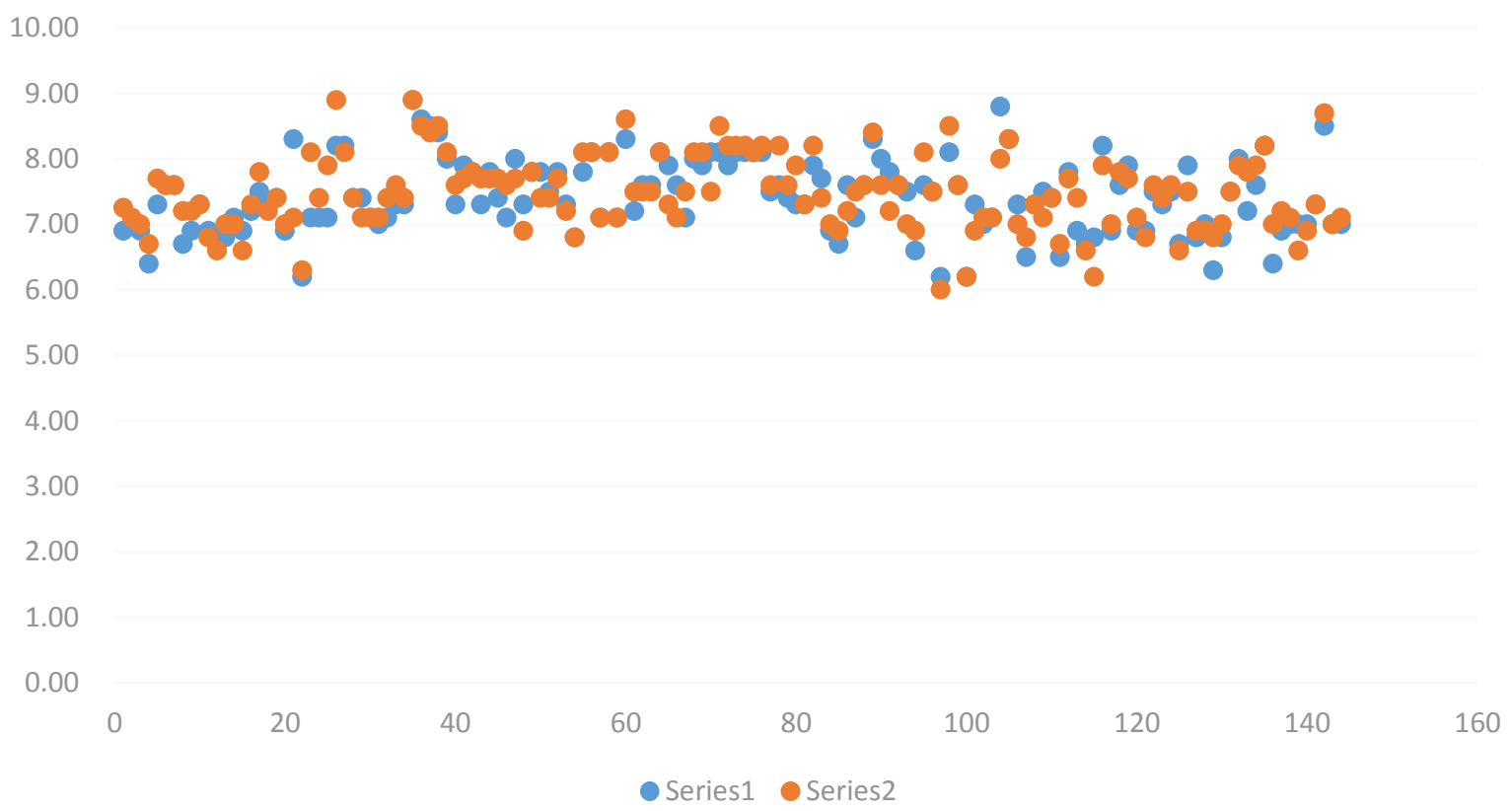




\section{AJAST}

Asian Journal of Applied Science and Technology

Volume 4, Issue 4, Pages 21-37, October-December 2020

5. Graph showing left index and left ring finger in case of males-

\section{Chart Title}

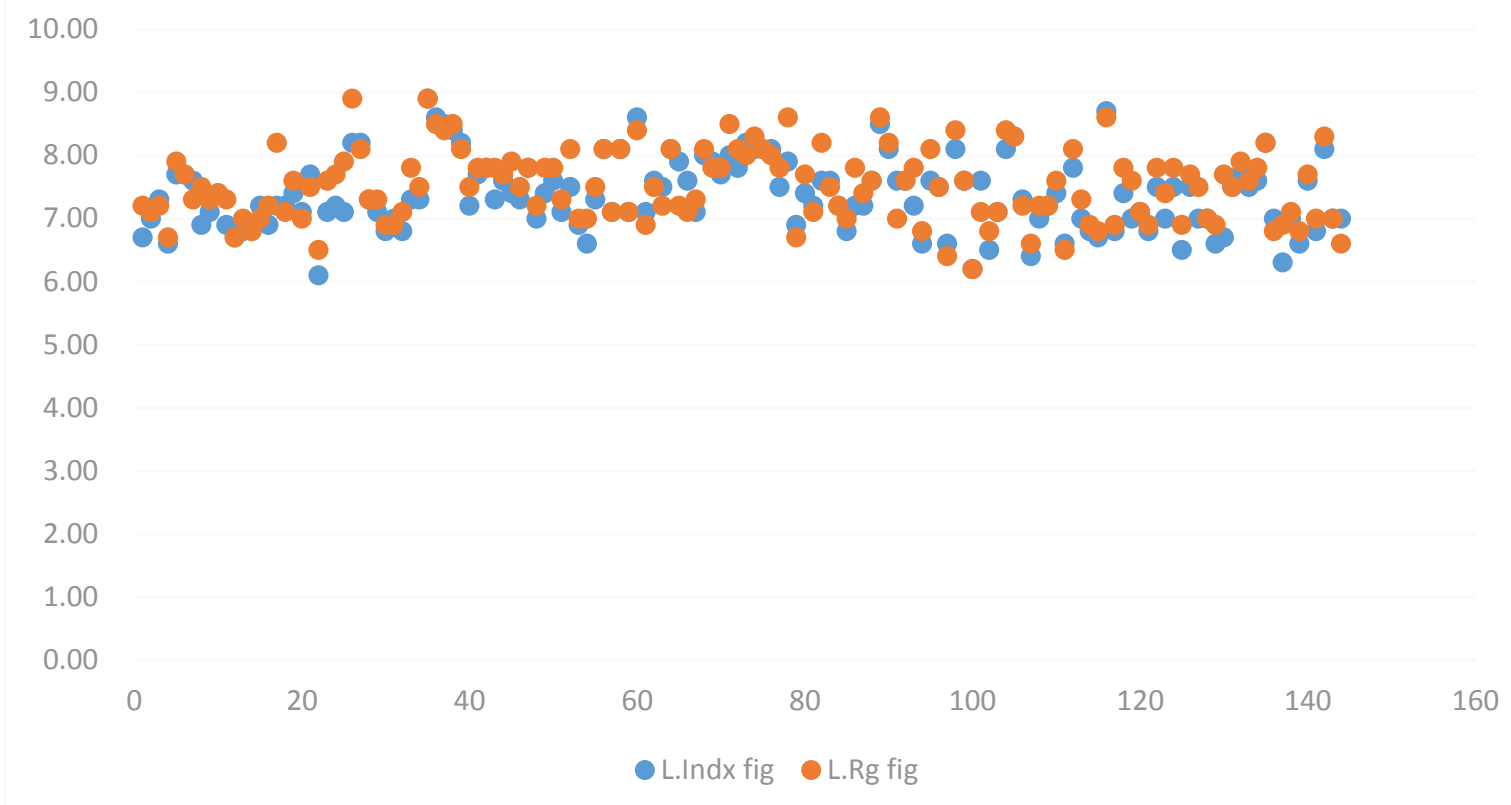

6. Graph showing right and left hand length in case of males-

\section{Chart Title}

25.00

20.00

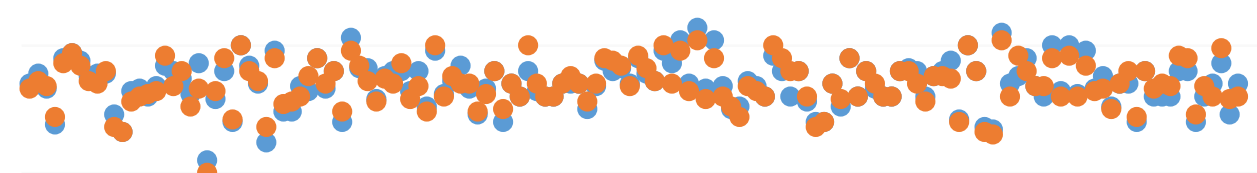

15.00

10.00

5.00

0.00

0

40

60

80

100

120

140 


\section{AJAST}

Asian Journal of Applied Science and Technology Volume 4, Issue 4, Pages 21-37, October-December 2020

7. Graph showing hand breadth of both the hands in case of females-

\section{Chart Title}

\subsection{0}

10.00

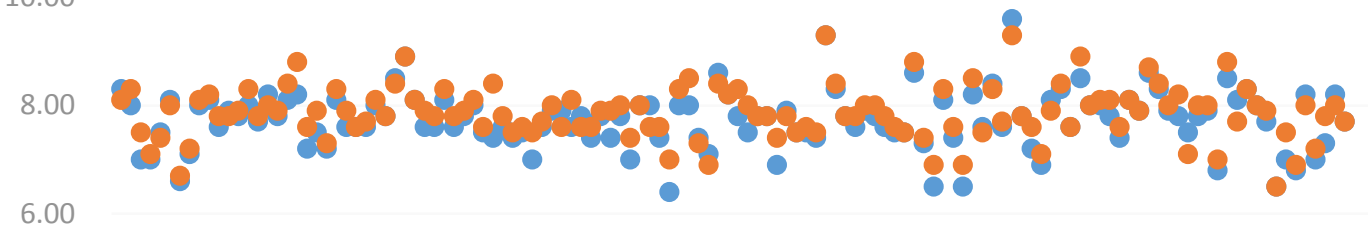

4.00

2.00

0.00

$\begin{array}{llllllll}0 & 20 & 40 & 60 & 80 & 100 & 120 & 140\end{array}$

8. Graph showing hand breadth of both the hands in case of males-

\section{Chart Title}

12.00

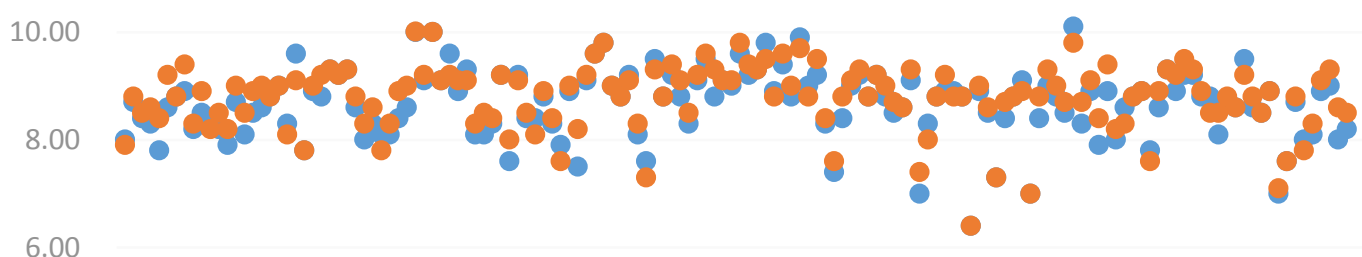

4.00

2.00

0.00

0

20

40

60

80

100

120

140

160

- L.H.B R.H.B 
9. Graph showing hand length of both the hands via t- test in case of females-

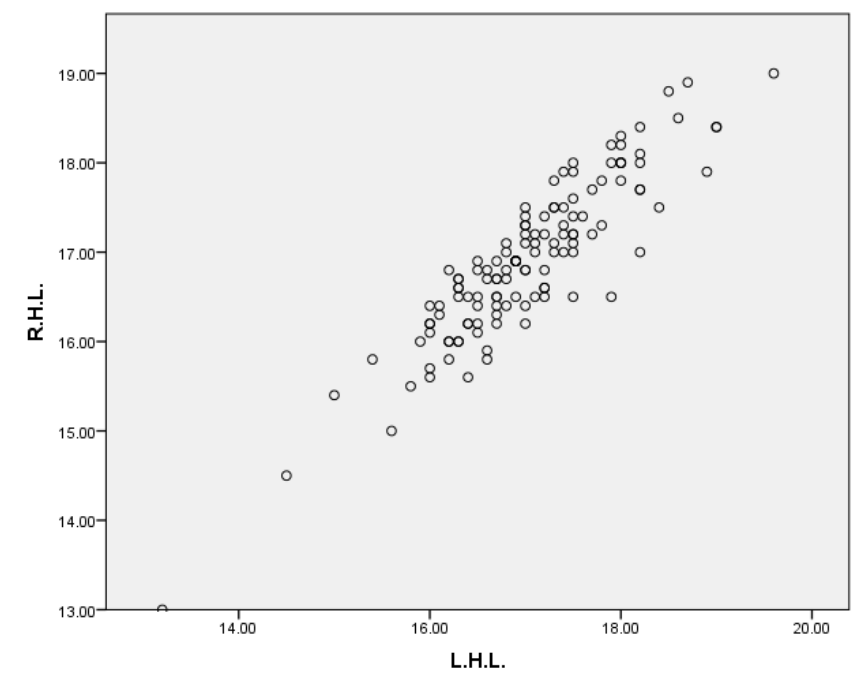

10. Graph showing hand breadth of both the hands via t-test in case of females-

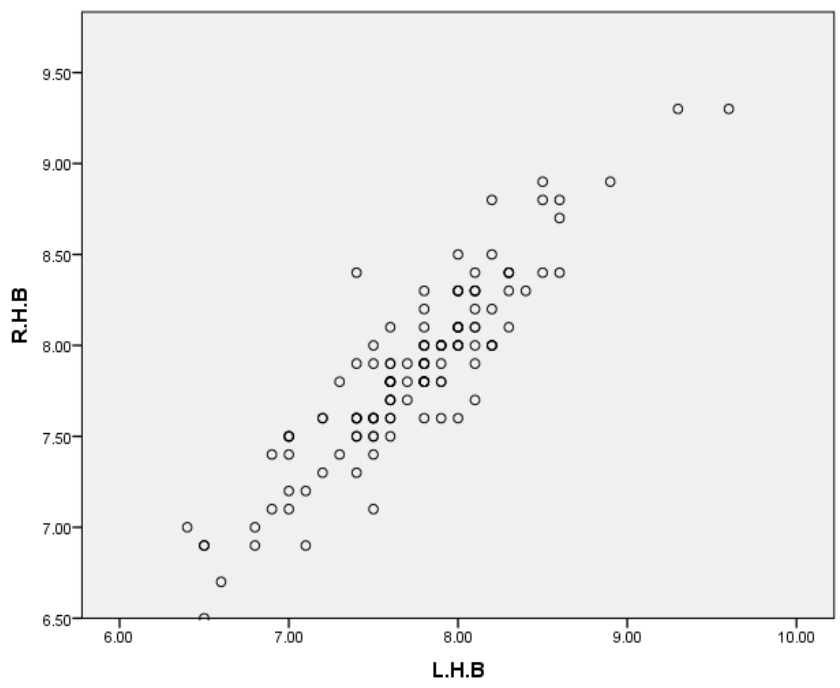

11 Graph showing index finger of both the hands via t-test in case of females-

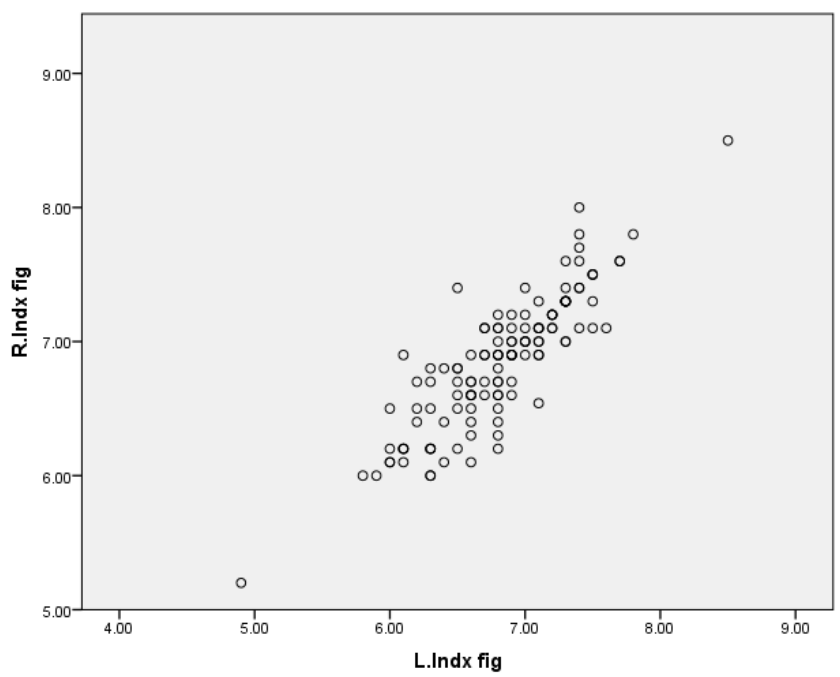


12 Graph showing ring finger of both the hands via t-test in case of females-

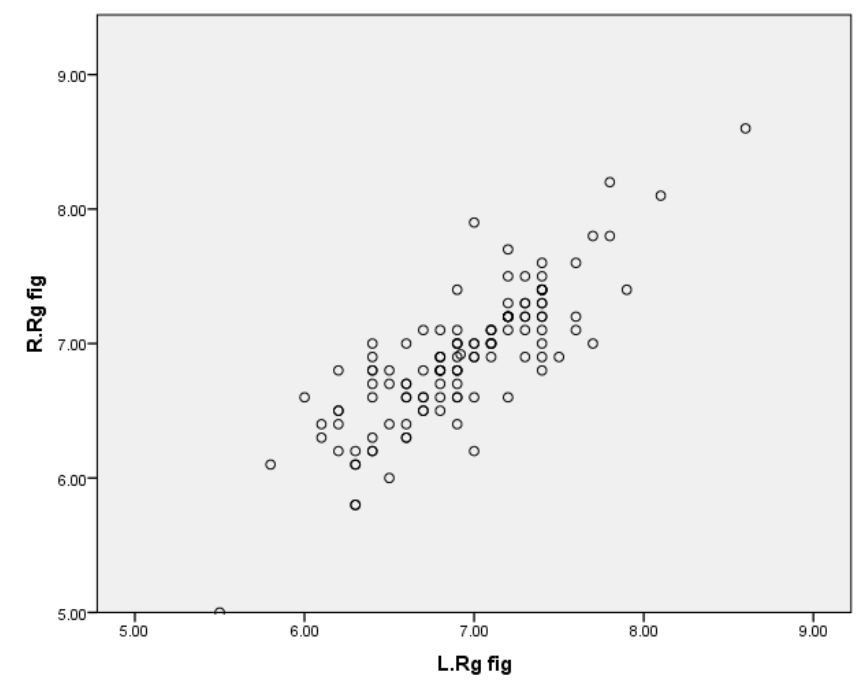

13 Graph showing hand length of both the hands via t-test in case of males-

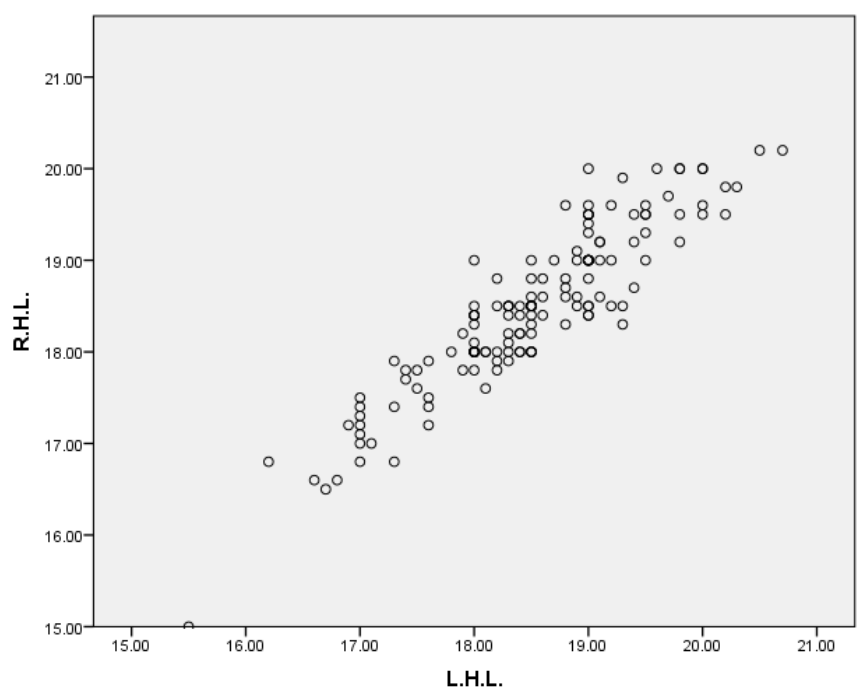

14 Graph showing hand breadth of both the hands via t-test in case of males-

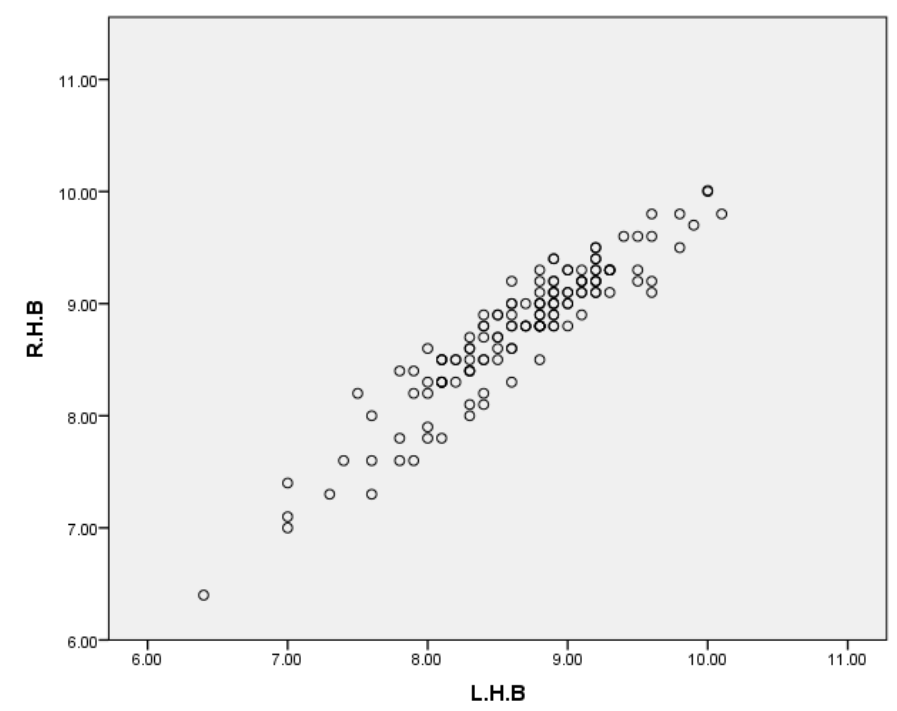


15 Graph showing index finger of both the hands via t-test in case of males-

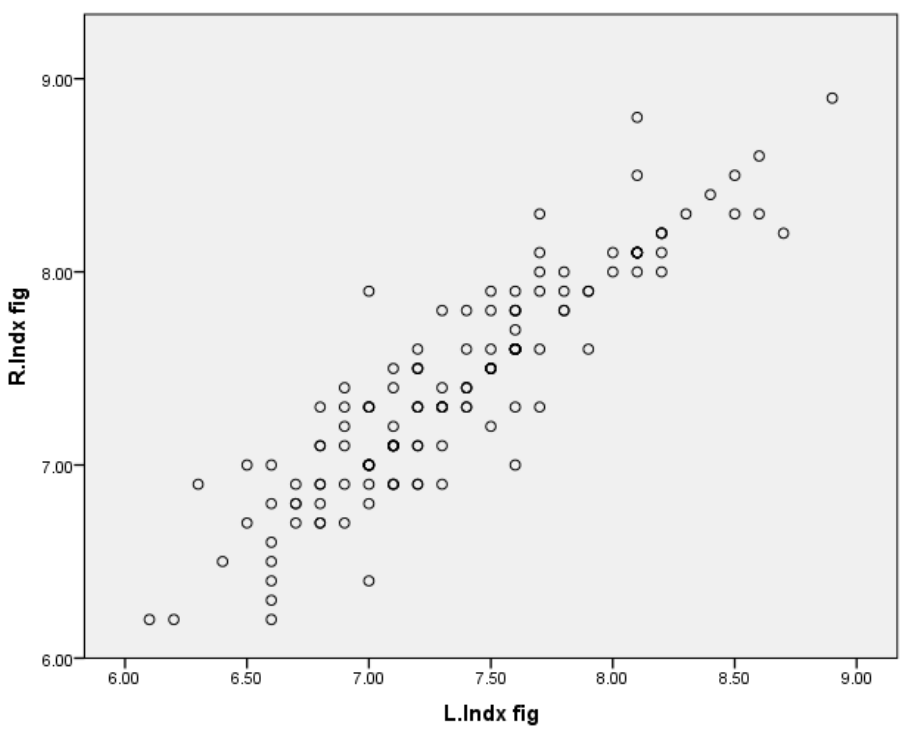

16 Graph showing ring finger of both the hands via t-test in males-

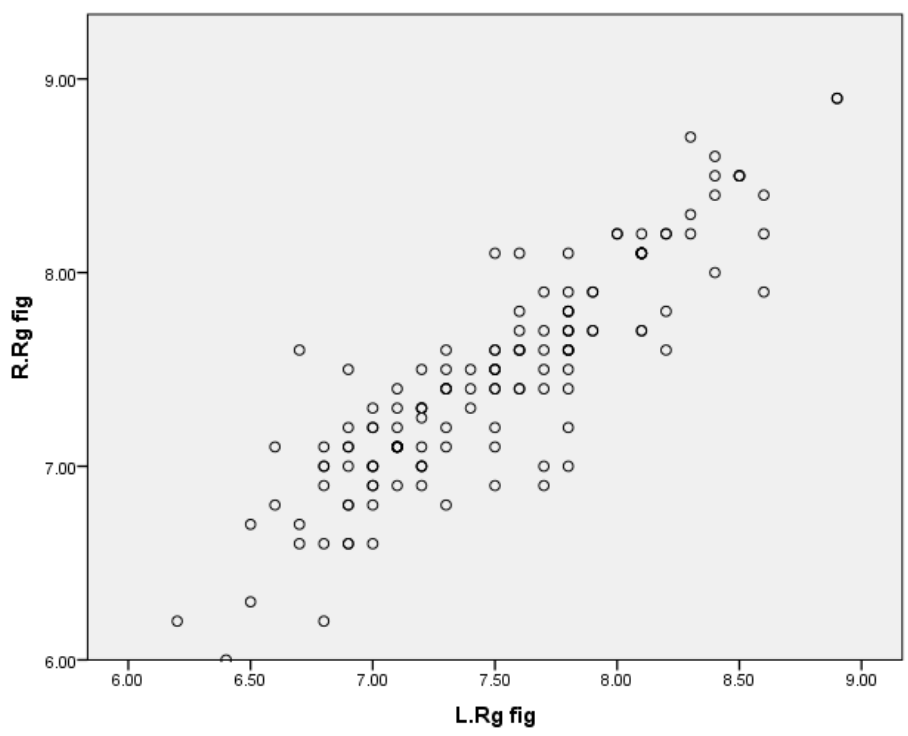

